\title{
Methodology for Structuring and Bundling Product-Service Systems
}

\author{
Michael Riesener ${ }^{1}$, Christian Dölle ${ }^{1}$, Julian Kreß ${ }^{1}$, Carsten Boßmann ${ }^{1}$, Günther Schuh ${ }^{1}$ \\ ${ }^{1}$ Laboratory for Machine Tools and Production Engineering (WZL) \\ of RWTH Aachen University
}

\begin{abstract}
Companies from the mechanical and plant engineering sector are increasingly offering Product-Service Systems (PSS) because they are facing greater competitive pressure within their industry. Furthermore, they perceive a stronger demand for holistic solutions by the customer. A single company is often unable to provide the PSS fully on its own because it may not have all competencies for its provision. Therefore, companies organize themselves in so-called corporate value networks. In order to assign individual components of the PSS to partners for provision, the PSS must be structured and the components of the PSS must be bundled. These bundles are formed based on the interdependencies between the components and can consist of both tangible product and intangible service components. This paper presents a methodology for structuring a PSS and creating a PSS architecture. A Multiple Domain Matrix is used to evaluate and display the interdependencies among the PSS components.
\end{abstract}

Keywords: Product-Service System, Clustering, Structuring, Architecture, Multiple Domain Matrix

\section{Introduction}

The machinery and plant engineering sector is currently facing increasing competitive pressure, mainly due to more intense international competition (Schuh et al., 2017). Differentiation based on physical products solely is becoming increasingly difficult, as the functional, price and quality levels of products are converging. In addition, the customer demand for end-to-end solution concepts is rising, resulting in an increasing amount of companies that are transforming themselves from product providers to solution providers (Schuh and Dölle, 2021). To this end, companies may offer services as a supplement to the actual product range (Aurich et al., 2016). The service sector is predicted to grow in importance, but the benefit for customers must be clearly recognizable, if they aim to obtain the solution for their problem holistically from one provider. Too often, companies offer services only as an add-on to physical products (Aagaard, 2019). However, if services are combined with physical products to Product-Service Systems (PSS) they offer a greater benefit. This requires a holistic development approach for the product and service components, so that customer requirements for PSS will be addressed in the best possible way (Schuh and Gudergan, 2016). In particular, interdependencies between the individual components, including those between products and services, must be examined in this context (Zou et al., 2018). Based on the components of the products and services and their interdependencies with one another, bundles can be put together, which should be as homogeneous as possible among each other. This has the advantage that these bundles can 
be handed over to external partners of a corporate value network for provision, since companies often do not have the necessary competencies in all required areas to be able to offer PSS holistically to the customer. Consequently, before allocating the bundles to companies, their competencies and capabilities must be analyzed in order to ensure targetoriented provision (Mont, 2002; Riesener et al., 2020). However, a corresponding methodology that can determine bundles within the PSS and visualizes interdependencies between product and service components and their functions does not exist. Therefore, a consistent description, structuring and decomposition of a PSS is required. The use of Design Structure Matrices (DSM) and Domain Mapping Matrices (DMM) is very suitable for this purpose.

\section{Fundamentals and Definitions}

First of all, the relevant fundamentals and definitions in the context of PSS and the structuring of products and services are presented. PSS consist of both tangible product components and intangible service components (Goedkoop et al., 1999). A product is henceforth defined as a tangible economic good, which is created in a production process and contributes to the satisfaction of a customer's need. A service is an immaterial economic good, which consists of processes and activities and is created and consumed simultaneously with the strong involvement of the customer (uno-acto principle) and thus cannot be created in stock. According to Baines et al., two development processes took place in parallel for the evolution of products and services into PSS. On the one hand, "servitization" of a product manufacturer takes place by first offering additional services before distributing PSS and on the other hand, "productization" of a service provider takes place by first offering additional products in return before distributing integrated products and services as PSS (Baines et al., 2007). It is particularly important that the individual product and service components are aligned with each other so that the overall benefit of a PSS for the customer is greater than the sum of the partial benefits of products and services (Salewski, 2016). This coordination leads to a higher complexity, but complexity is both a cause and a consequence of providing PSS. Initially, the complexity of the products increases and associated services become necessary in order to fully exploit the potential of the products (Burianek, 2009). Offering PSS leads to changes in business models, since the focus is not on selling a product but on providing a solution. According to Tukker, PSS can be marketed with three different business model types. In a product-oriented business model, provision focuses on the classic sale of products with the additional offer of services. The benefit-oriented business model guarantees the usability of the products. The third type consists of the result-oriented business models, in which the customer pays only for the output of a PSS (Tukker, 2004).

The structuring of the PSS is one prerequisite for identifying interdependencies in the individual product and service components. For this purpose, the concept of product architecture is applied analogously, which can be used to structure physical products. The concept of product architecture was significantly published by Ulrich in the literature (Ulrich, 1995). The product architecture consists of three elements: The functional structure describes the decomposition of the product function into sub-functions resulting from the product requirements. The second element of a product architecture is the product structure. For this, the product is broken down into its components and the relations 
Michael Riesener, Christian Dölle, Julian Kreß, Carsten Boßmann, Günther Schuh

between the components are represented in a hierarchical structure. The last element consists of the transformation relations, which show the connections between the components and sub-functions (Schuh and Riesener, 2017).

\section{Related Work}

In this section, related scientific work is examined. The presented approaches are sorted into two groups focusing either on structuring products or services or on structuring the PSS itself.

In scientific literature, many approaches mainly focus on the development of product components in a PSS. Service components are seen as an add-on that are provided additionally to the product components. AlGeddawy and ElMaraghy present a methodology for creating a product architecture in consideration of the degree of granularity. This approach of hierarchical clustering originates in the research area of biological systematics but is used for tangible products. The result of this methodology is a structure of a product in its components but in an optimal degree of granularity (AlGeddawy and ElMaraghy, 2013). The approach of Mannweiler and Aurich focuses on the development of an architecture for PSS. In this architecture, product and service components are matched with functions of the PSS. Since this is an appropriate way to structure PSS, Mannweiler and Aurich prioritize the product components within their architecture. Therefore, this approach is not comprehensive enough to consider all parts of a PSS (Mannweiler and Aurich, 2013). The methodology of Hölttä-Otto et al. focuses mainly on service components of a PSS. Starting from a portfolio consisting only of products, services are examined and assigned to a corresponding lifecycle phase of a product. This allows the company to create PSS. Nevertheless, product and service components have to be linked together during the development process of a PSS (HölttäOtto et al., 2012). Similarly, Rabe presents an approach that enables the conceptual design of smart services for existing mechatronic systems. The core of the approach is a reference architecture with reference modules, which represents the desired principle solution of the smart service in a model-based manner. A compatibility matrix can then be used to determine the combination of individual reference modules for addressing a specific application scenario, taking into account the available data and interfaces of the underlying mechatronic system during conceptual design (Rabe, 2020). Lubarski and Poeppelbuss support with their approach the systematic selection of methods for service modularization. For this purpose, they develop a framework for systematizing existing methods in this research field. The framework addresses methods that support the modularization of services and does not focus on PSS as an integrated solution consisting of service and product components and their interdependencies (Lubarski and Poeppelbuss, 2016). For the knowledge-oriented development of PSS, Schenkl's two-stage approach focuses on the integration of end-to-end knowledge management into the development process. Based on a systematic knowledge management and available company knowledge, existing products are subsequently enriched by product-accompanying services to PSS. The approach focuses only on the development of product-accompanying services based on existing corporate knowledge and takes only a limited look at the sphere of product components (Schenkl, 2015). 
Besides approaches, which focus mainly on product or service components, there are also approaches that focus on the structuring of the PSS. Aurich et al. present a methodology that configures a PSS according to their current phase within the product lifecycle. Appropriate service components are matched to the products. This approach includes the structuring of the products as well as the structuring of the services. Nevertheless, product and service components are not developed simultaneously (Aurich et al., 2009). Sun et al. pursue a similar objective with their approach, which aims to support the customer-specific and modular composition of PSS. By means of a fuzzy cluster algorithm, functional requirements are combined into requirement clusters, which in turn form the basis for the subsequent definition of modules consisting of product and service components. For the methodology to be elaborated, the approach forms a relevant basis, whereby aspects of the PSS architecture are not considered (Sun et al., 2017). The contribution of Song and Sakao supports the development of PSS by a standardized reference development process addressing four successive development steps starting with the identification of requirements as well as technical attributes up to the modularization and concept configuration. Field-proven methods are embedded in the process while modularization of PSS is playing only a minor role (Song and Sakao, 2017). The approach of Bartoschek provides a possibility to determine the variety of offers of a PSS. Regarding information from customers, strategical guidelines and costs of realization, an optimal level of granularity according to the value and the costs of a PSS can be accomplished (Bartoschek, 2011).

In conclusion, services in PSS are often offered only as add-ons to existing products. There is no integrated and holistic description and structuring of the PSS aiming for an integrated PSS architecture. Furthermore, there is no overall decomposition logic for PSS that can be used as a basis for bundling product and service components. Consequently, these bundles, which should be as independent as possible, can be provided to some extent by partners of the corporate value network. This paper presents a methodology that addresses the scientific deficits regarding the structuring and bundling of PSS.

\section{Methodology}

The methodology consists of five successive steps, as shown in Figure 1. In the first and second step, the PSS is structured with the help of a functional structure as well as a product and service structure. These three structures form the foundation for clustering PSS components to PSS bundles. In order to be able to use an algorithm for clustering, a Multiple Domain Matrix (MDM) has to be set up, which is part of the third step. Based on the elaborated interdependencies of the PSS components, in the fourth step bundles are defined using the IGTA-plus algorithm. Subsequently, the PSS architecture is developed in the fifth and last step of the methodology. 


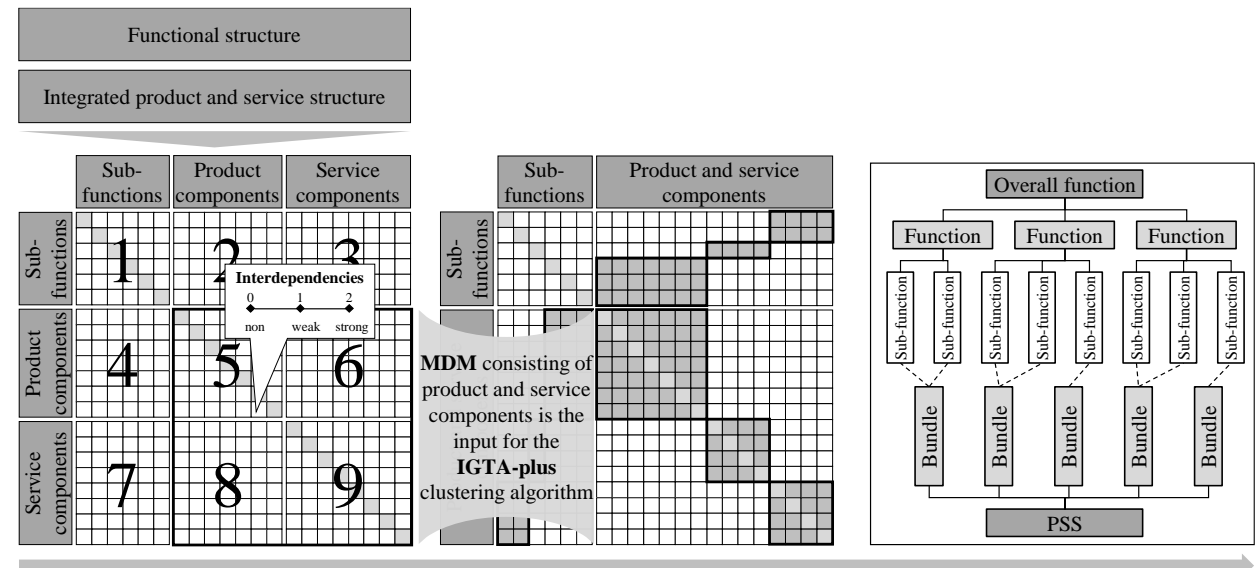

Figure 1. Overview of relevant steps of the methodology for structuring and bundling PSS resulting in a PSS architecture

The first step is to elaborate a functional structure that is aligned with the value proposition of the underlying business model. For the customer benefit-centric alignment of the PSS, it is first necessary to determine relevant requirements for the PSS, whereby the use of the Value Proposition Canvas according to Osterwalder et al. has proven to be suitable. The Value Proposition Canvas consists of two parts, the Customer Profile and the Value Map. With the help of the Customer Profile, a comprehensive understanding of the customer is created by working out the "job-to-be-done" and the associated customers pains and gains. The Value Map defines how value is created for the customer by identifying gain creators and pain relievers. Gain creators describe how products and services create customer gains, while pain relievers describe how products and services alleviate customer pains (Osterwalder et al., 2014). Necessary products and services that address the most relevant gain creators and pain relievers have to be included in the PSS. For the determination of the most relevant gain creators and pain relievers, a pairwise comparison can be used. At the same time, the prioritized gain creators and pain relievers represent the customer requirements regarding the PSS. The most relevant customer requirements are translated into functions and hierarchically combined into the functional structure.

The second step of the methodology describes the set-up of the integrated product and service structure. The methodical foundation of a product structure has been sufficiently described in the scientific literature (Göpfert, 1998). However, it is important that the product structure is built up in the right level of detail. If the level of granularity is selected too narrow, it will neither be possible to create reasonable bundles in a PSS, nor will it be possible to use the termination criterion when creating the architecture. Furthermore, it is necessary that all physical components of the PSS are included in the product structure even those that are used for the provision of services. Approaches for creating a service structure do not exist, but the structure can be built in analogy to the product structure, since the principle of hierarchical decomposition can also be applied here (Burr, 2016; Gill, 2003). In an analogy analysis, a comparison of the similarities between the objects under consideration is conducted. Based on this, a decision can be made whether an analogous 
transfer or a transfer with need for modification is possible (Haberfellner et al., 2019). In the present case, the differences are primarily the uno-actu principle of the services, the focus on processes and activities, the stronger customer involvement in the creation process, and the intangibility. This is counteracted by numerous similarities. In particular, the divisibility into components, assignment of the components to partial functions, the existence of hierarchical relations and the description of interfaces need to be mentioned here. In summary, it can be stated that despite some differences, the similarities of products and services predominate and thus an analogous transfer of the product structure on services is possible. This guarantees that the structuring of a PSS considers all product and service components. Nevertheless, the structures of the product and service components have so far been considered separately, so that there is still no integrated view on the components of a PSS. In order to create an integrated PSS architecture, the product and service components must be analyzed with regard to their interdependencies, which is the objective of the following step.

The bundling of components of the PSS is another important aspect of this methodology. Subsequently it is possible, that individual bundles of PSS components can be handed over to partners within a corporate value network for their provision. Since the process of bundling shall be conducted automatically with an algorithm, a matrix with numerical values is required. For this purpose, the third step of the methodology describes the set-up of a MDM, which is the input for the clustering algorithm implemented in MATLAB. In the MDM, the three domains sub-functions, product components and service components are included. This results in a matrix with nine fields, in which the interdependencies between the components of the PSS and the sub-functions must be evaluated. Due to the different number of elements in the individual domains, the MDM consists of Design Structure Matrices (DSM) on the diagonal fields and Domain Mapping Matrices (DMM) as displayed in Figure 1. (Browning, 2001; Danilovic and Börjesson, 2001; Steward, 1981). Interdependencies are assessed using a three-level logic from 0 (no interdependencies), 1 (weak interdependencies) up to 2 (strong interdependencies) to allow a better description of the interdependencies in contrast to the original two-level logic. This allows a gradation of the strength of interdependencies to be realized with little effort, for which the available information is sufficiently precise. First, the function-related interdependencies are determined. These exist on the one hand between the sub-functions themselves and between the sub-functions and the product and service components. The investigation of the function-related interdependencies is particularly important because after the creation of bundles it is possible to evaluate whether the bundles are functionally independent. Since this favors outsourcing to partners within the corporate value network, functional interdependency represents an optimization criterion. Next, the interdependencies of the product and service components are determined. The four matrices used for this purpose form their own MDM, which can be used as input for the clustering algorithm. These matrices are displayed in Figure 1 with the numbers 5, 6, 8 and 9. Within this MDM, all combinations of components of the PSS must be examined and evaluated for interdependencies. In some cases, these interdependencies are known from the product or service structure. Once again, a level of granularity, which is too narrow, is not beneficial for the analysis of the interfaces between the individual components. Therefore, the interfaces must be considered at a superordinate level, since the components have not been resolved at a fine granular level either. However, there are dependencies when service 
components relate to product components or require them for an execution. These evaluations are used to generate a matrix that serves as input for the cluster algorithm.

In the fourth step of the methodology, the bundling of the components of the PSS, is conducted with the IGTA-plus algorithm. This algorithm is based on the well-known IGTA algorithm (Gutierrez Fernandez, 1998; Idicula, 1995; Thebeau, 2001), but is improved significantly in terms of the singular assignment of elements to clusters, the replicability of calculations and the shorter calculation time. To ensure the mentioned benefits, the empirically determined values for the parameters of the algorithm according to Borjesson and Hölttä-Otto are used. For the calculation, all interdependencies are assigned to costs. The costs of the interdependencies within a cluster are thereby lower than the interdependencies of the elements of different clusters. The algorithm minimizes the total costs incurred (Borjesson and Hölttä-Otto, 2012). The algorithm is applied in MATLAB and the data input is implemented as a matrix with numerical values. This matrix is created in step 3. The result of the application of the algorithm is a matrix whose elements are arranged according to the calculated clusters as shown in Figure 1. Finally, the functional independence of the bundles is checked. Since the bundles should be as independent as possible, optimization measures can start at this point.

Based on the bundles developed in the previous step, a PSS architecture can be created in the fifth and last step. The architecture consists of three elements, similar to a product architecture: The PSS structure, the functional structure and the transformation relationships as shown in Figure 1. The functional structure is already known from the first step of this methodology. The PSS structure is established from the bundles that have been created using the algorithm based on the interdependencies between the individual product and service components. At this point, all PSS components have thus been considered holistically. The transformation relationships also result from the bundles and the MDM, since the assignment of the sub-functions to the components of the PSS has already been conducted. With the support of this PSS architecture, it is therefore possible to consider and structure a PSS and its components holistically.

\section{Case study}

In the section at hand, the presented methodology is validated within a case study. For this purpose, a PSS is used, which is offered in the context of a result-oriented business model, where the customer buys a pre-determined volume of compressed air from the supplier. The supplier is responsible for the operation of the compressor and the generation of the compressed air. On the one hand, the PSS consists of the compressor and its components as well as other tangible components necessary for the operation of the compressor. On the other hand, the associated services are ranging from demand analysis and financing to service and performance review, as well as dismantling and disposal of the system. In total, the PSS consists of 19 product components and nine service components, which are included in the MDM. Next, the interdependencies are evaluated according to the presented three-level logic, so that the resulting matrix can be used as the input for the IGTA-plus algorithm. After executing the algorithm, six bundles emerge. Three of these bundles consist of both product and service components. An example is bundle three, which is consisting of the electric motor, the screw compressor, the intake filter, the compressed air 
tank as well as the preparation of the requirements analysis and the solution concept. The results show that bundles can consist precisely of product and service components. Furthermore, a joint bundling of the components is necessary to structure a PSS and an integrated approach has to be chosen. Since the bundles are as independent as possible of each other, these bundles can be more easily handed over to a partner within the corporate value network, if this is required due to the availability of the necessary competencies for delivery. Figure 2 visualizes the results as an exemplary excerpt.
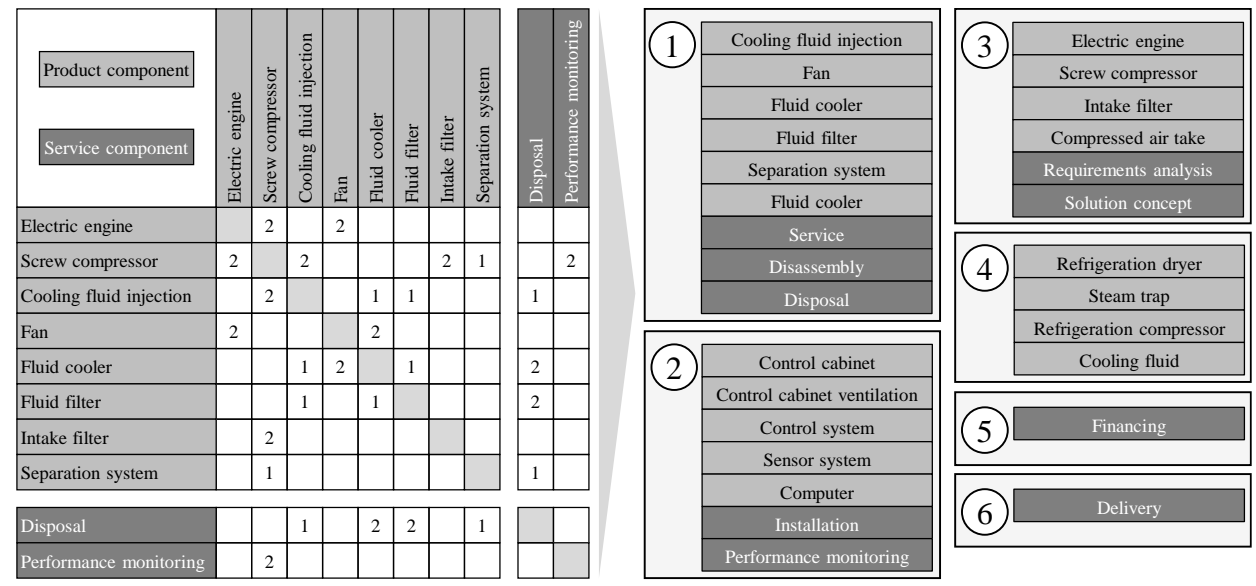

Figure 2. Excerpt of the evaluation of interdependencies among product and service components in MDM and resulting bundles

\section{Conclusion}

Companies of the machinery and plant engineering sector offer PSS because the sector faces more competitive pressure and the possibilities for technical differentiation are limited. In addition, the significance of services and the customer demand for solutions instead of standalone products is rising. Therefore, companies transform themselves to solution providers. As PSS increase the benefit for customers, product and service components of the PSS have to be developed holistically. This paper presents a methodology to structure a PSS into bundles consisting of product and service components. The approach consists of five consecutive steps from building a functional structure to applying the IGTA-plus algorithm for clustering. The methodology proves that bundles consisting of product and service components are helpful to structure the PSS within an architecture in which the bundles are as independent from each other as possible. In consequence, this method supports the provider of the PSS to structure all components of the PSS and to prepare a decision, which bundles can be handed over to a partner within a corporate value network for their development and provision. In order to be able to make this decision, a competence analysis focusing on the required and existing competences of the PSS provider would be the next step. Finally, potential cooperation partners can be identified to close the competence gap of the PSS provider and the corporate value network can be set up. The mentioned next steps are part of the research activities of the authors. 


\section{Acknowledgment}

Funded by the Deutsche Forschungsgemeinschaft (DFG, German Research Foundation) under Germany's Excellence Strategy - EXC-2023 Internet of Production - 390621612.

\section{References}

Aagaard, A., 2019. The Concept and Frameworks of Digital Business Models, in: Aagaard, A. (Ed.), Digital Business Models. Springer International Publishing, Cham, pp. 1-26.

AlGeddawy, T., ElMaraghy, H., 2013. Optimum granularity level of modular product design architecture. CIRP Annals - Manufacturing Technology 62, 151-154.

Aurich, J.C., Kölsch, P., Herder, C.F., Mert, G., 2016. PSS 4.0 - Einflüsse von Industrie 4.0 auf Produkt-Service Systeme. Zeitschrift für wirtschaftlichen Fabrikbetrieb 111, 565-568.

Aurich, J.C., Wolf, N., Siener, M., Schweitzer, E., 2009. Configuration of product-service systems. Journal of Manufacturing Technology Management 20, 591-605.

Baines, T.S., Lightfoot, H.W., Evans, S., Neely, A., Greenough, R., Peppard, J., Roy, R., Shehab, E., Braganza, A., Tiwari, A., Alcock, J.R., Angus, J.P., Bastl, M., Cousens, A., Irving, P., Johnson, M., Kingston, J., Lockett, H., Martinez, V., Michele, P., Tranfield, D., Walton, I.M., Wilson, H., 2007. State-of-the-art in product-service systems. Proceedings of the Institution of Mechanical Engineers, Part B: Journal of Engineering Manufacture 221, 1543-1552.

Bartoschek, M.A., 2011. Effektive Angebotsvielfalt industrieller Leistungssysteme, 1st ed. Apprimus-Verl., Aachen.

Borjesson, F., Hölttä-Otto, K., 2012. Improved Clustering Algorithm for Design Structure Matrix, in: Proceedings of the ASME International Design Engineering Technical Conferences and Computers and Information in Engineering Conference - 2012, Chicago. ASME (Veranst.), New York, pp. 921-930.

Browning, T.R., 2001. Applying the Design Structure Matrix to System Decomposition and Integration Problems: A Review and New Directions. IEEE Transactions on Engineering Management 48, 292-306.

Burianek, F., 2009. Vertragsgestaltung bei hybriden Leistungsangeboten: Eine ökonomische Betrachtung. Diss., 1st ed. Gabler Verlag, München.

Burr, W., 2016. Service Engineering bei technischen Dienstleistungen: Eine ökonomische Analyse der Modularisierung, Leistungstiefengestaltung und Systembündelung, 2nd ed. Springer, Wiesbaden.

Danilovic, M., Börjesson, H., 2001. Participatory Dependence Structure Matrix Approach. Proceedings of the 3rd Dependece Structure Matrix (DSM) International Workshop.

Gill, C., 2003. Architektur für das Service Engineering zur Entwicklung von technischen Dienstleistungen. Shaker, Aachen.

Goedkoop, M., van Haler, C., te Riele, H., Rommers, P., 1999. Product-Service Systems, ecological and economic basics. Report for Dutch Ministries of Environment (VROM) and Economic Affairs (EZ).

Göpfert, J., 1998. Modulare Produktentwicklung: Zur gemeinsamen Gestaltung von Technik und Organisation. Deutscher Universitätsverlag, München.

Gutierrez Fernandez, C.I., 1998. Integration analysis of product architecture to support effective team co-location. Boston.

Haberfellner, R., Weck, O.L. de, Fricke, E., 2019. Systems Engineering: Fundamentals and Applications. Springer, Cham.

Hölttä-Otto, K., Tang, V., Otto, K., 2012. Module Definition for Product-Service Systems, in: . ASME 2012 International Design Engineering Technical Conferences and Computers and Information in Engineering Conference, Chicago. 12.-15. August 2012. American Society of Mechanical Engineers, New York, pp. 359-368.

Idicula, J., 1995. Planning for concurrent engineering. Singapur. 
Lubarski, A., Poeppelbuss, J., 2016. Methods for Service Modularization - A Systematization Framework, in: . PACIS 2016 Proceedings.

Mannweiler, C., Aurich, J.C., 2013. Modularization of Products and Services for Configuring Product-Service Systems, in: Shimomura, Y., Kimita, K. (Eds.), The Philosopher's Stone for Sustainability: Proceedings of the 4th CIRP International Conference on Industrial ProductService Systems, Tokyo, Japan, 2012. Springer, Berlin, Heidelberg, pp. 37-41.

Mont, O., 2002. Clarifying the concept of product-service system. Journal of Cleaner Production 10, 237-245.

Osterwalder, A., Pigneur, Y., Bernarda, G., Smith, A., Papadakos, P., 2014. Value Proposition Design: How to create products and services customers. Wiley, Hoboken, NJ.

Rabe, M., 2020. Systematik zur Konzipierung von Smart Services für mechatronische Systeme.

Riesener, M., Dölle, C., Kress, J., Schuh, G., 2020. Methodology for the Assessment of Complexity in Corporate Value Networks, in: 2020 IEEE International Conference on Industrial Engineering and Engineering Management (IEEM), Singapore, Singapore. 2020. IEEE, pp. 445-449.

Salewski, H., 2016. Modularisierung im Kontext der Servicetransformation - Herausforderungen undOptimierungsansätze, in: Bruhn, M., Hadwich, K. (Eds.), Servicetransformation: Entwicklung vom Produktanbieter zum Dienstleistungsunternehmen. Springer Fachmedien Wiesbaden, Wiesbaden, pp. 351-371.

Schenkl, S.A., 2015. Wissensorientierte Entwicklung von Produkt-Service-Systemen.

Schuh, G., Dölle, C., 2021. Sustainable Innovation: Nachhaltig Werte schaffen. Springer, Berlin.

Schuh, G., Gudergan, G., 2016. Einführung und Grundlagen des Managements industrieller Dienstleistungen, in: Schuh, G., Gudergan, G., Kampker, A. (Eds.), Management industrieller Dienstleistungen: Handbuch Produktion und Management 8, 2nd ed. Springer, Berlin, pp. 1-20.

Schuh, G., Riesener, M., 2017. Produktkomplexität managen: Strategien - Methoden - Tools, 3rd ed. Hanser, München.

Schuh, G., Salmen, M., Jussen, P., Riesener, M., Zeller, V., Hensen, T., Begovic, A., Birkmeier, M., Hocken, C., Jordan, F., Kantelberg, J., Kelzenberg, C., Kolz, D., Maasem, C., Siegers, J., Stark, M., Tönnes, C., 2017. Geschäftsmodell-Innovation, in: Reinhart, G. (Ed.), Handbuch Industrie 4.0: Geschäftsmodelle, Prozesse, Technik. Hanser, München, pp. 3-30.

Song, W., Sakao, T., 2017. A customization-oriented framework for design of sustainable product/service system. Journal of Cleaner Production 140, 1672-1685.

Steward, D.V., 1981. The Design Structure System: A Method for Managing the Design of Complex Systems. IEEE Transactions on Engineering Management 28, 71-74.

Sun, J., Chai, N., Pi, G., Zhang, Z., Fan, B., 2017. Modularization of product service system based on functional requirement. Procedia CIRP 64, 301-305.

Thebeau, R.E., 2001. Knowledge Management of System Interfaces and Interactions for Product Development Processes. Boston.

Tukker, A., 2004. Eight types of product-service system: eight ways to sustainability? Experiences from SusProNet. Business Strategy and the Environment 13, 246-260.

Ulrich, K., 1995. The role of product architecture in the manufacturing firm. Research Policy 24, 419-440.

Zou, W., Brax, S.A., Rajala, R., 2018. Complexity in Product-Service Systems: Review and Framework. Procedia CIRP 73, 3-8.

Contact: Julian Kreß, Laboratory for Machine Tools and Production Engineering (WZL) of RWTH Aachen University, Department Innovation Management, Campus-Boulevard 30, 52074 Aachen, Germany,j.kress@wzl.rwth-aachen.de 